\title{
Suppression of prostate tumor cell survival by antisense oligonucleotide-mediated inhibition of $A R-V 7$ mRNA synthesis
}

\author{
Maria V. Luna Velez ${ }^{1} \cdot$ Gerald W. Verhaegh $^{1} \cdot$ Frank Smit $^{2} \cdot$ J. P. Michiel Sedelaar ${ }^{1} \cdot$ Jack A. Schalken $^{1}$
}

Received: 5 July 2018 / Revised: 12 December 2018 / Accepted: 4 January 2019 / Published online: 21 January 2019

(c) The Author(s) 2019. This article is published with open access

\begin{abstract}
One of the mechanisms by which advanced prostate cancer develops resistance to androgen deprivation therapy is the elevated expression of C-terminally truncated androgen receptor (AR) variants. These variants, such as AR-V7, originate from aberrant splicing of the $A R$ pre-mRNA and the inclusion of a cryptic exon containing a premature stop codon in the mRNA. The resulting loss of the ligand-binding domain allows AR-V7 to act as a constitutively active transcription factor. Here, we designed two antisense oligonucleotides (AONs) directed against cryptic splicing signals within the $A R$ premRNA. These two AONs, AON-ISE and AON-ESE, demonstrated high efficiency in silencing $A R-V 7$ splicing without affecting full-length AR expression. The subsequent downregulation of AR-V7-target gene UBE2C was accompanied by inhibition of androgen-independent cell proliferation and induction of apoptosis in castration-resistant prostate cancer (CRPC)-derived cell line models 22Rv1, DuCaP, and VCaP. Our results show that splicing-directed AONs can efficiently prevent expression of $A R-V 7$, providing an attractive new therapeutic option for the treatment of CRPC.
\end{abstract}

\section{Introduction}

Despite the clinical remission achieved by androgen deprivation therapy, advanced prostate cancer eventually progresses into recurrent or castration-resistant prostate cancer (CRPC) [1]. CRPC is a lethal disease with no curative treatment available and with a median survival of 1-2 years [2, 3]. One mechanism of CRPC progression is the elevated expression of androgen receptor splice variants (AR-Vs). Although many AR-Vs have been described, $A R$ splice variant $7(A R-V 7)$ is the most commonly and abundantly expressed variant in human CRPC tissues $[4,5]$. ARV7 expression is correlated with a bad prognosis and a high

Supplementary information The online version of this article (https:// doi.org/10.1038/s41388-019-0696-7) contains supplementary material, which is available to authorized users.

Jack A. Schalken

Jack.Schalken@radboudumc.nl

1 Department of Urology, Radboud Institute for Molecular Life Sciences, Radboud university medical center, Nijmegen, The Netherlands

2 MDxHealth, Nijmegen, The Netherlands probability of disease recurrence [4-7]. AR-V7 lacks the ligand-binding domain (LBD) and is constitutively active, i.e., it can promote androgen-independent cell proliferation in vitro [8] and tumor growth in vivo under castrate androgen levels [5]. Due to the lack of the LBD, its activity is insensitive to the AR antagonists, bicalutamide and enzalutamide, agents currently used as prostate cancer therapeutics [8-11].

$A R-V 7$ originates from alternative splicing of the $A R$ premRNA. A typical splicing process requires the coordinated action of splicing factors and cis-acting regulatory elements. Intron 3 of the $A R$ contains two splicing signals known as intronic and exonic splicing enhancers (ISE and ESE, respectively). Recognition of these cis elements by the splicing machinery results in the inclusion of a cryptic exon 3 (CE3) into the mRNA. This cryptic exon includes a premature stop codon leading to the synthesis of AR-V7 [12]. Blocking these signals could prevent splicing and inclusion of $\mathrm{CE} 3$, leading to the expression of a full-length $A R$ mRNA (AR-FL) and this potentially could be used as a mean to re-sensitize tumor cells to current androgen deprivation therapy.

Antisense oligonucleotides (AONs) are single stranded, short molecules that can block (aberrant) splicing events by base-pairing with cryptic splice sites in the pre-mRNA in the nucleus $[13,14]$. In the present study, we describe the 


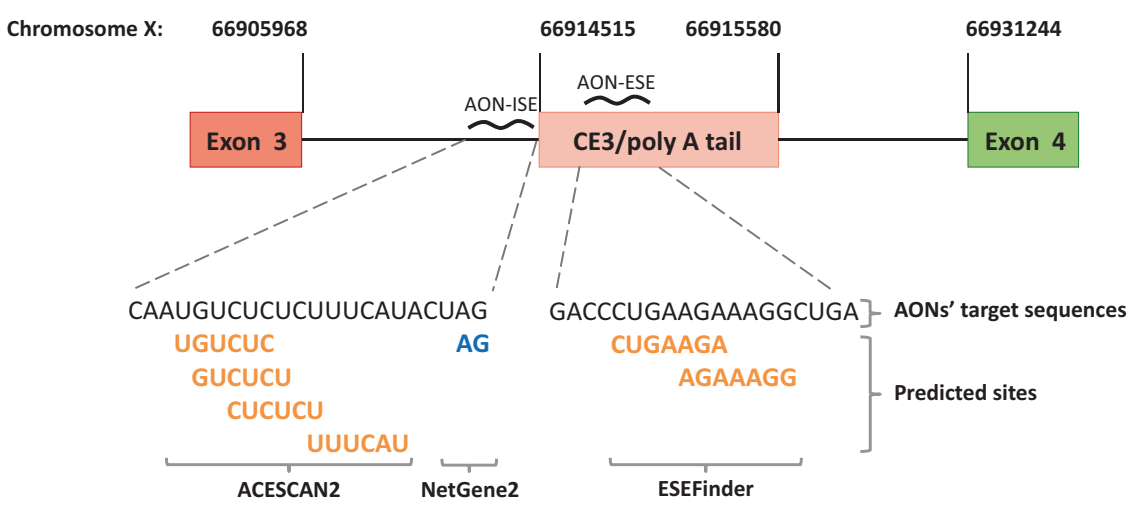

Fig. 1 Design of antisense oligonucleotides (AONs). Schematic representation (not to scale) of the AONs designed to prevent splicing of androgen receptor $(A R)$ pre-mRNA into $A R$ - $V 7$ mRNA. AON-ISE is complementary to the intronic splicing enhancer (ISE) sites predicted by ACESCAN2, and the cryptic "GA" splice acceptor dinucleotide motif, predicted by NetGene2. AON-ESE is complementary to the region harboring the ESEfinder-predicted exonic splicing enhancer (ESE) sites. Predicted splicing enhancer sites are bold and yellow, and the predicted cryptic splice acceptor site is on blue. The corresponding genomic coordinates (Human Genome Assembly February 2019, HG19) are marked by vertical lines pointing at the $5^{\prime}$ and/ or $3^{\prime}$ junctions of exon 3 , cryptic exon 3 (CE3), and exon 4 use of AONs to prevent $A R-V 7$ mRNA synthesis in CRPCderived cell line models 22Rv1, DuCaP, and VCaP. We show that splicing-directed AONs specifically and efficiently knockdown expression of this variant. The AONmediated suppression of AR-V7 has an inhibitory effect of androgen-independent cell proliferation. Our results provide the first proof of principle for the use of splice-switching AONs in CRPC and highlights their potential as therapeutic agents.

\section{Results}

\section{Identification of cis-acting splicing enhancer elements in AR CE3}

For the identification of cis-acting splicing enhancer elements within the so-called CE3 sequence $[4,5]$ and its flanking regions, we used the publically available computer-based algorithms ACESCAN2 [15] and ESEFinder $[16,17]$ to predict potential ISE and ESE sites, respectively. Four ISE sites were identified in the flanking region upstream of CE3 and its cryptic splice acceptor (SA) site. This SA site was detected by screening the same sequence with the NetGene2 server [18]. Two ESE sites were found close to the $3^{\prime}$ end of the CE3 sequence. One AON, named AON-ISE, was designed such that it encompasses all four ISE motifs, as well as the detected cryptic SA site (Fig. 1). A second AON, designated AONESE, was designed encompassing both ESE motifs in CE3 (Fig. 1). Both AONs were generated with a phosphorothioate backbone [19] and 2'-O-methyl group modifications at the sugar chain $[20,21]$ to make them resistant to RNAse activity.

\section{AON-mediated suppression of AR-V7 mRNA synthesis and expression}

Next, we evaluated the splicing inhibitory potential of the AONs in vitro. An $A R$ minigene was created with CE3 and its flanking regions inserted in between exon 3 and exon 4 and flanking regions of the human $A R$ gene (Fig. 2a). The $A R$ minigene was transiently transfected into AR-negative MIA-PaCa-2 cells (Supplementary Fig. S1A), and both an $A R-F L$ (exon 3-exon 4) and an $A R$-V7 (exon 3-CE3) transcript were expressed, suggesting that canonical and alternative splicing occurs in the minigene-encoded $A R$ transcript (Fig. 2b). Of note, a natural preference for canonical splicing was apparent as levels of the $A R-F L$ transcript were almost twofold higher than those of $A R-V 7$ transcript. Minigenetransfected MIA PaCa-2 cells were subsequently treated with either AON-ISE or AON-ESE. Both splicing-directed AONs displayed a significant reduction of $A R-V 7$ transcript expression but did not affect the expression levels of $A R-F L$ (Fig. 2b). Interestingly, the AON directed against the ESE was less efficient in the knockdown of $A R$ - $V 7$ than the one directed against the ISE. The specificity of both AONs was assessed by transfecting control oligonucleotides containing the AON sequence in the sense orientation. Neither of the sense oligonucleotides, SON-ISE or SON-ESE, affected the levels of either $A R$ minigene-encoded transcript, whereas expression levels were comparable to non-treated minigeneexpressing cells (Fig. 2b).

We further tested the AONs ability to knockdown $A R-V 7$ in the CRPC-derived DuCaP and VCaP cell line models. Both cell lines express $A R-F L$ and $A R-V 7$ at levels comparable to those from CRPC specimens (Supplementary Fig. S1A,B). Upon addition of either AON, a strong decrease in $A R-V 7$ mRNA expression was noted in both cell 

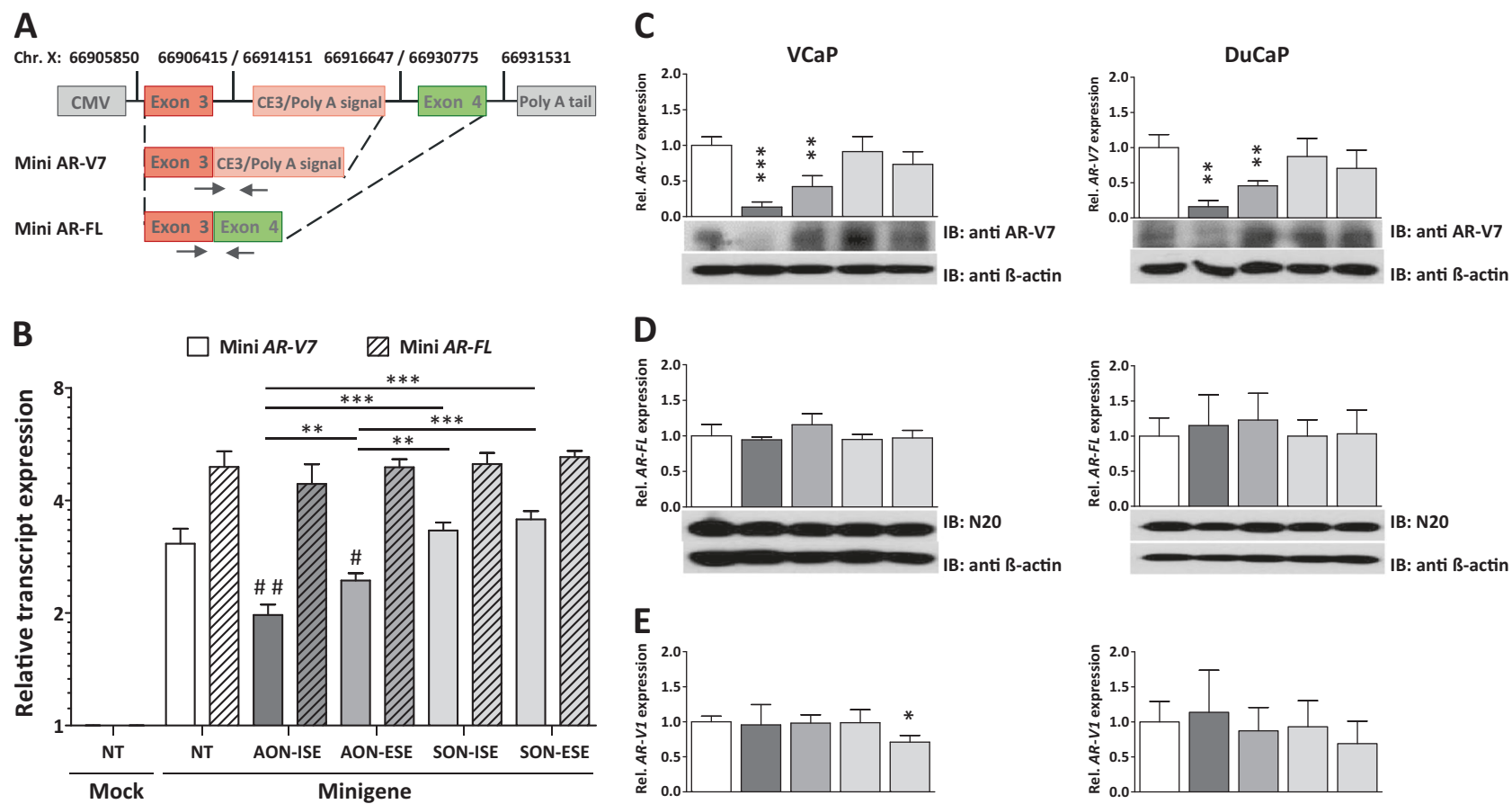

D
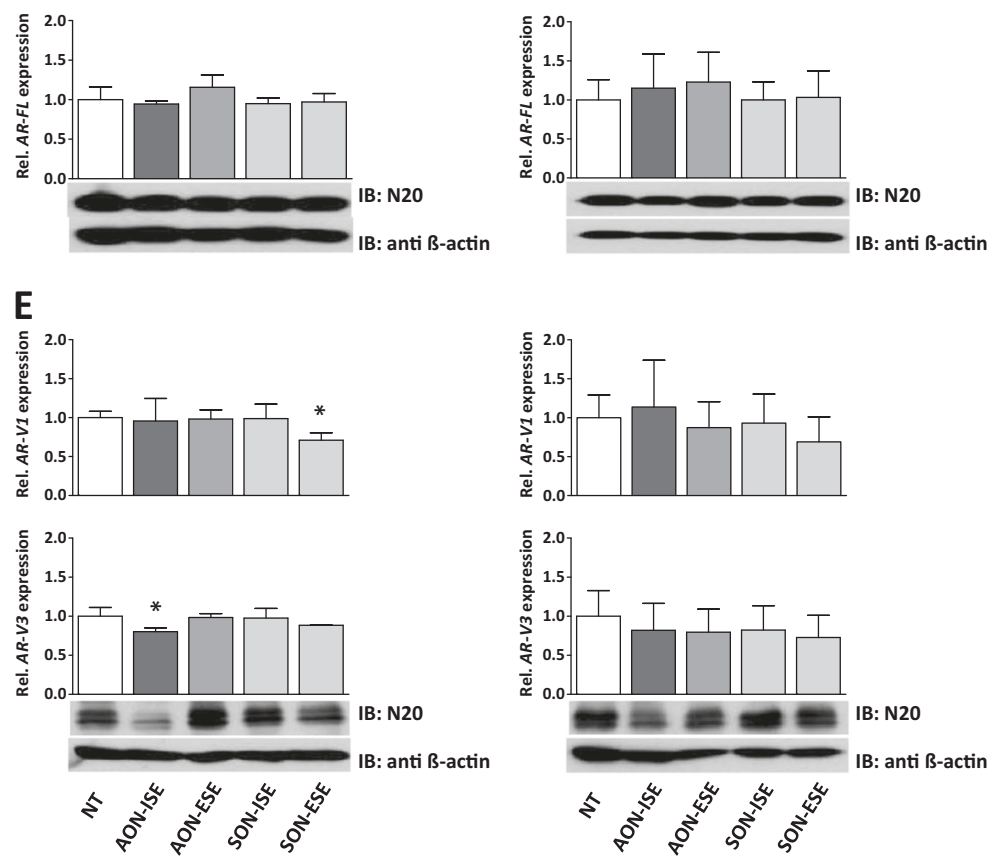

Fig. 2 Antisense oligonucleotide (AON)-mediated AR-V7 knockdown. a Schematic diagram (not to scale) of the androgen receptor (AR) minigene construct. Minimal regions containing $A R$ exon 2, cryptic exon 3 (CE3), exon 4 and their flanking regions are cloned into a CMV-driven pEGFP-N3 expression vector. Vertical lines mark positions of each $A R$ gene fragment on chromosome $\mathrm{X}$ (Human Genome Assembly February 2019, HG19). Primers for RT-qPCR are marked with headed arrows. b AR-negative MIA PaCa-2 cells were transfected with $500 \mathrm{ng}$ AR minigene vector or with empty vector and with $0.5 \mu \mathrm{M}$ AONs (AON-intronic splicing enhancer (ISE) and AONexonic splicing enhancer (ESE)) or control sense oligos (SON-ISE and SON-ESE). Relative expression of AR-FL and AR-V7 from the AR

lines (Fig. 2c). Western blot analysis of whole-cell extracts using an AR-V7-specific antibody directed against CE3encoded amino acids showed a reduction of AR-V7 protein levels upon treatment with the AONs (Fig. 2c). Treatment with control SONs did not affect $A R-V 7$ mRNA or protein levels. $A R-F L$ mRNA, as well as protein levels, remained unchanged upon treatment with AONs (Fig. 2d). Because $\mathrm{CE} 3$ lies in close proximity to other intronic regions that can serve as cryptic exons to generate other AR variants, such as $A R-V 1$ or $A R-V 3$, we assessed the expression levels of these variants. $A R-V 1 \mathrm{mRNA}$ levels were not affected in neither cell line. However, $A R-V 3$ expression was significantly reduced in $\mathrm{VCaP}$ upon addition of AON-ISE, albeit to a minigene were measured by RT-qPCR analysis, four days after transfection. Unpaired $t$-test; $* * p<0.01 ; * * * p<0.001$. AON-treated vs non-treated cells; ${ }^{\#} p<0.05$ and ${ }^{\# \#} p<0.01$. Bars represent the mean $\pm \mathrm{SD}$ of three independent experiments. c-e Expression levels of $A R$ $V 7, A R-F L, A R-V 1$, and $A R-V 3$ in DuCaP and VCaP cells (determined by RT-qPCR), 4 days after transfection with $0.2 \mu \mathrm{M}$ AONs or control oligos. Expression levels were compared with non-transfected cells (NT). Below each graphs, western blot analysis of AR-V7 (anti-ARV7), AR-FL (N20), and truncated AR-Vs (N20) protein levels are shown. Protein levels of $\beta$-actin (anti- $\beta$-actin) were used as protein loading control. Unpaired $t$-test; ${ }^{*} p<0.05 ;{ }^{* *} p<0.01 ; * * * p<0.001$. Bars represent the mean \pm SD of three independent experiments

lesser extent than that of AR-V7 expression. Staining with an AR N-terminus-specific antibody (N20) detected two protein bands of about $75 \mathrm{kDa}$. The upper band had the same size as the translated product in AR-V7-transfected HeLa cells (data not shown), suggesting it corresponds to endogenous AR-V7 protein levels $(67 \mathrm{kDa})$. This band was weakened after treatment with AON-ISE, similarly to band detected with AR-V7-specific antibody. Interestingly, the lower molecular size band ( $\sim 66 \mathrm{kDa})$ was also reduced in $\mathrm{VCaP}$ cells, presumably corresponding to AR-V3 (Fig. 2e). Altogether, these results showed that AONs complementary to the splice enhancer motifs in and around CE3 can efficiently prevent AR-V7 mRNA synthesis in vitro. 

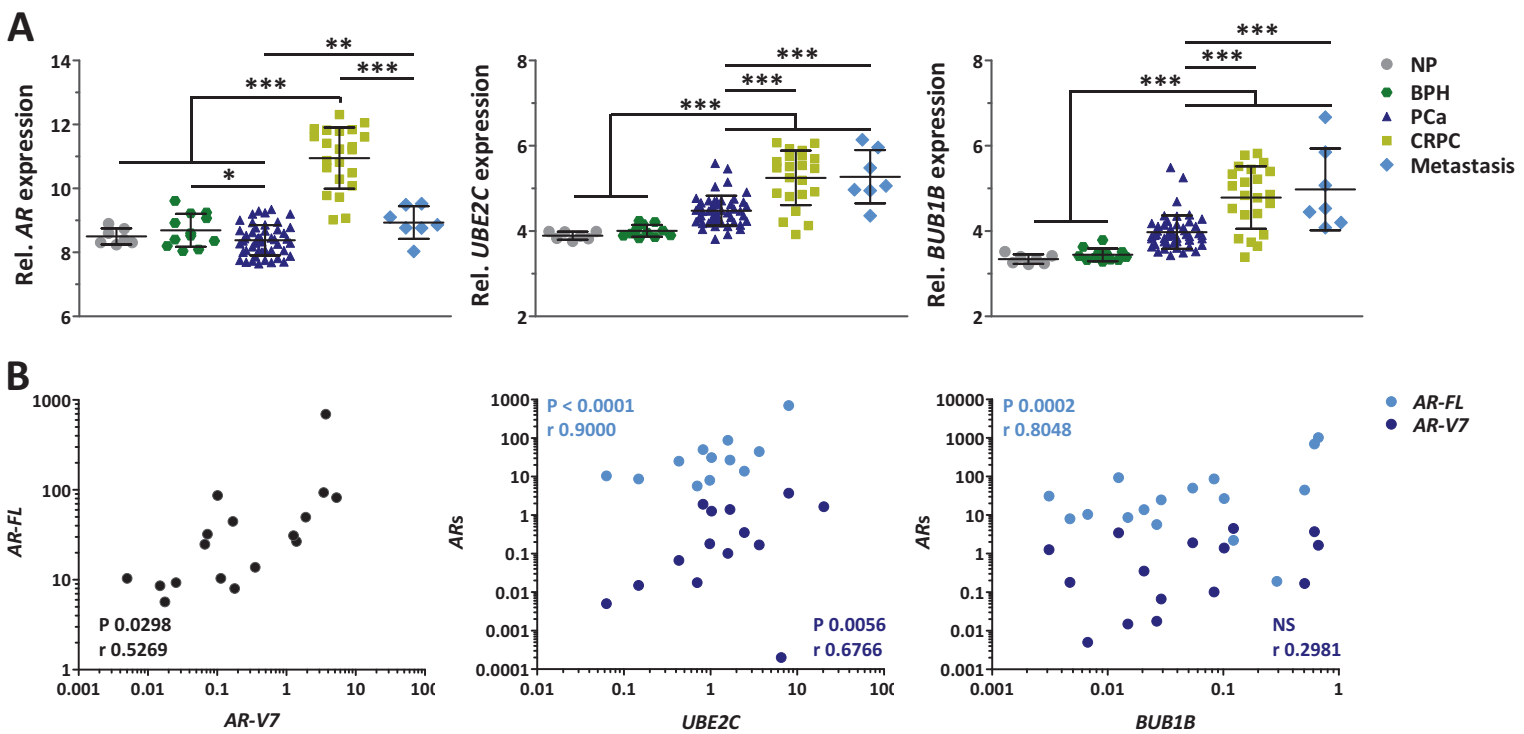

C

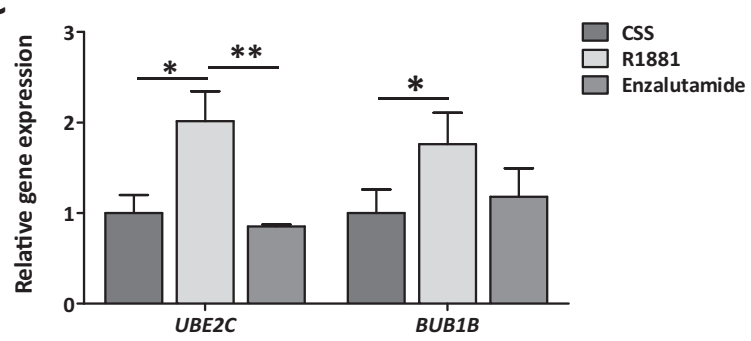

D

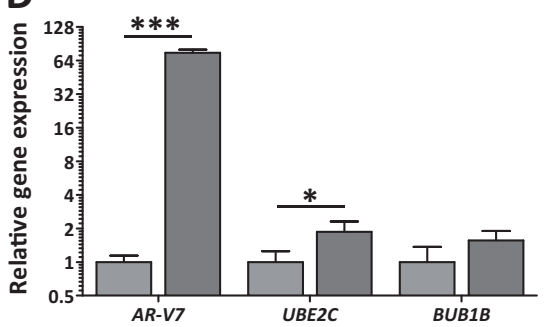

E
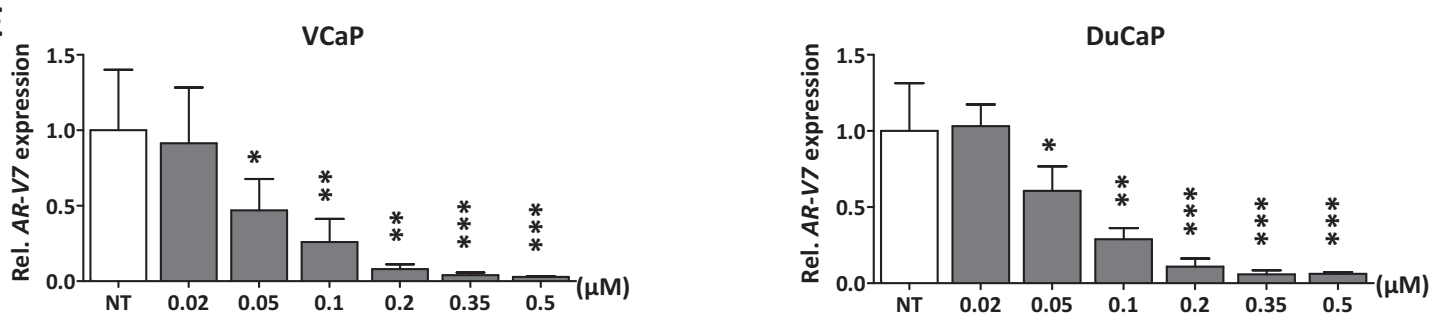

$\mathbf{F}$
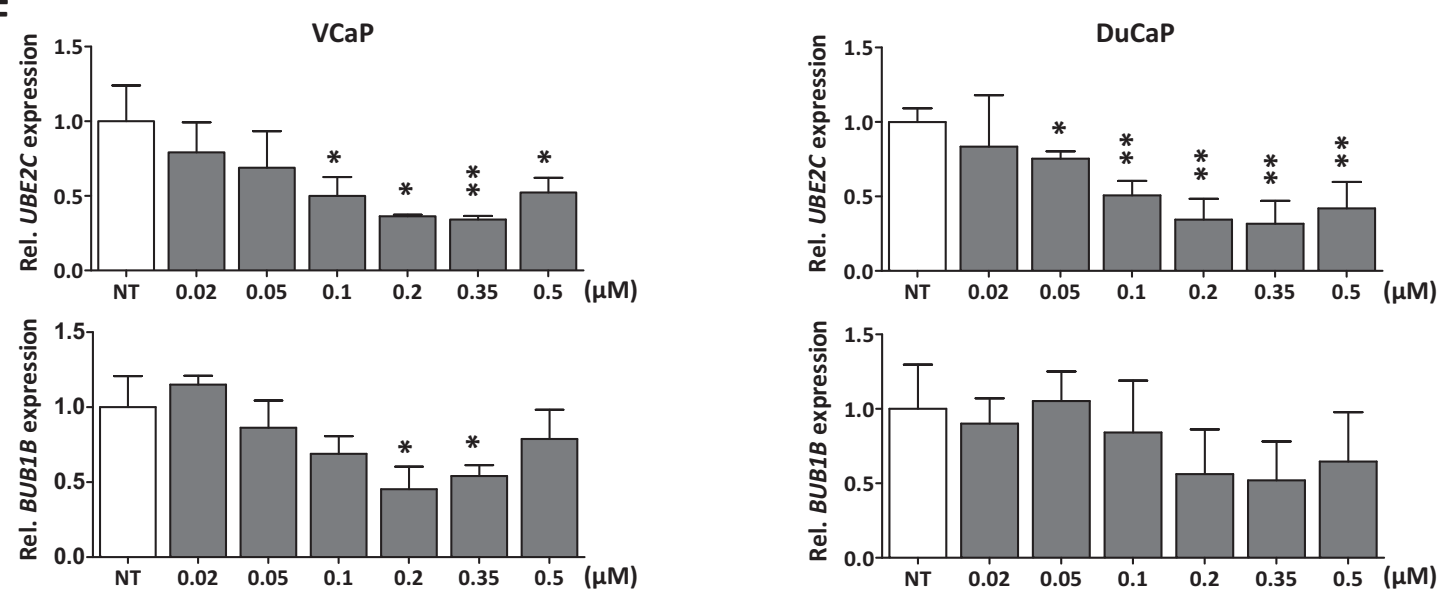
Fig. 3 Effect of antisense oligonucleotide (AON)-intronic splicing enhancer (ISE) on androgen receptor (AR)-V7-targeted gene expression. a Microarray analysis showing $A R, U B E 2 C$, and $B U B 1 B$ gene expression profiles in normal prostate (NP, $n=7)$, benign prostate hyperplasia ( $\mathrm{BPH}, n=12)$, primary prostate cancer $(\mathrm{PCa}, n=49)$, castration-resistant prostate cancer (CRPC, $n=22)$, and metastasis ( $n$ $=7)$. Microarray values $(2 \log$ scale are shown as the mean \pm SD of each group is depicted. Unpaired $t$-test; $* * p<0.01 ; * * * p<0.001)$. b Pearson correlation of $A R-F L, A R-V 7, U B E 2 C$, and $B U B 1 B$ mRNA expression, obtained by RT-qPCR, in CRPC $(n=20)$ specimens. Two-tailed $p$-values and Pearson $r$ values are depicted. NS; $p>0.05$. c Relative $U B E 2 C$ and $B U B 1 B$ mRNA expression in $\mathrm{VCaP}$ cells, determined $96 \mathrm{~h}$ after treatment with $0.1 \mathrm{nM}$ R1881, or R1881 in combination with $2 \mu \mathrm{M}$ enzalutamide. Unpaired $t$-test; $* p<0.05 ; * * p$ $<0.01$; $* * * p<0.001$. Bars represent the mean \pm SD of three independent experiments. d Relative mRNA expression levels of $A R-V 7$, $U B E 2 C$, and $B U B 1 B$ in $\mathrm{VCaP}$ cells following transfection with an ARV7 expression vector. Unpaired $t$-test; ${ }^{*} p<0.05$; $* * * p 0.001$ ). Bars represent the mean $\pm \mathrm{SD}$ of three independent experiments. e, $\mathbf{f}$ Relative mRNA expression from $A R-V 7$ (e), $U B E 2 C$ and $B U B 1 B$ (f) in $\mathrm{DuCaP}$ and $\mathrm{VCaP}$ cells, as determined $96 \mathrm{~h}$ after treatment with increasing doses of AON-ISE, compared with non-transfected cells (NT). Unpaired $t$-test; $* p<0.05$; $* * p<0.01$; ***p $<0.001$. Bars represent the mean \pm SD of three independent experiments

\section{AON-mediated knockdown of AR-V7 results in downregulation of AR-V7-target genes}

AR-Vs have been described to have an overlapping but distinct transcriptional output than AR-FL [6, 22]. Among the genes described to be regulated by AR-Vs, specifically by AR-V7, are the cell cycle regulatory genes $U B E 2 C$ and $B U B 1 B[8,11]$. Microarray analysis of prostate (cancer) specimens showed that, similarly to $A R$ expression, $U B E 2 C$ and $B U B 1 B$ are significantly upregulated in CRPC tissue compared with benign tissues and androgen-sensitive primary prostate cancer and metastatic tissues (Fig. 3a). To be able to discriminate between $A R-F L$ and $A R-V 7$ expression, a qPCR validation was performed using CRPC samples from an independent cohort. Both $A R-F L$ and $A R-V 7$ expression positively correlated with the expression of $U B E 2 C$, but only $A R-F L$ correlated with $B U B 1 B$ expression (Fig. 3b).

We next assessed the dependency of $U B E 2 C$ and $B U B 1 B$ expression on AR-FL-mediated transactivation. Treatment of $\mathrm{VCaP}$ cells with androgens induced expression of ARtarget gene $K L K 3$ whereas treatment with enzalutamide, a new-generation (full-length) AR antagonist, inhibited it (Supplementary Fig. S2A). Androgen stimulation also resulted in a marked induction of $U B E 2 C$ and $B U B 1 B$, which was reverted with the addition of enzalutamide (Fig. $3 c)$. Forced expression of $A R-V 7$ in $\mathrm{VCaP}$ cells resulted in a significant upregulation of $U B E 2 C$ and a weak, but observable increase of $B U B 1 B$ expression (Fig. 3d). These last results were obtained from cells grown in androgendepleted medium, and hence this expression profile was considered a consequence of AR-V7 activity, exclusively.
From these results, it is clear that $U B E 2 C$ is part of both AR-FL and AR-V7 transcriptional program and, therefore, it can be used to monitor the efficiency of AON-induced $A R-V 7$ knockdown.

Because AON-ISE resulted in a more efficient reduction of $A R-V 7$ expression levels in both $\mathrm{DuCaP}$ and $\mathrm{VCaP}$ cells than AON-ESE, further experimentation did not include the latter AON. Cells were transfected with various concentrations of AON-ISE ranging from $0.02 \mu \mathrm{M}$ to $0.5 \mu \mathrm{M}$. A significant $A R$ $V 7$ knockdown was achieved with doses above $0.02 \mu \mathrm{M}$, with a clear dose-dependent decrease of $A R-V 7$ mRNA levels in both cell lines (Fig. 3e). The dose-dependent AON-ISEmediated knockdown of $A R-V 7$ resulted in a dose-dependent suppression of $U B E 2 C$. Although the maximum level of $A R$ $V 7$ splicing inhibition was achieved at $0.5 \mu \mathrm{M}$ AON-ISE, a dose of $0.35 \mu \mathrm{M}$ suppressed $U B E 2 C$ the most. Treatment with AON-ISE at a dose of $0.2 \mu \mathrm{M}$ and $0.35 \mu \mathrm{M}$ doses resulted in a significant downregulation of $B U B 1 B$ in $\mathrm{VCaP}$ cells, but the AON did not affect $B U B 1 B$ expression in DuCaP cells (Fig. 3f). AON-ISE treatment resulted in a specific $A R-V 7$ knockdown and subsequently downregulation of the AR-V7target gene, UBE2C.

Intra-chromosomal translocation of the transmembrane protease serine 2 (TMPRSS2) gene to the ETS family member $E R G$ is the most prevalent fusion in prostate cancer [23] and the fusion gene is expressed in the $\mathrm{VCaP}$ cell line. AR-V7, as well as AR-FL, have been described to mediate transcriptional activation of TMPRSS2 [4, 12, 24]. Interestingly, under castrated conditions, AON-ISE treatment of $\mathrm{VCaP}$ cells resulted in downregulation of TMPRSS2-ERG mRNA levels (Supplementary Fig. S2B), suggesting the involvement of AR-V7 in the transcriptional regulation of this fusion gene.

\section{Effects of AON-ISE-mediated AR-V7 knockdown on cell proliferation and apoptosis}

Prostate cancer cells rely on androgens for proliferation and survival, via activation of AR-FL and its targeted genes. One of the functional consequences of AR-V7 protein expression is its capacity to maintain proliferation of tumor cells in the absence of androgens. Thus, we evaluated the ability of AON-ISE to inhibit androgen-independent cell proliferation. To eliminate any contribution of AR-FL, cells were grown in androgen-depleted medium. A dosedependent effect on cell viability was observed in DuCaP and $\mathrm{VCaP}$ upon treatment with AON-ISE but not with control SONs (Fig. 4a). To exclude that the effect of AONISE on cell viability is AR independent, we assessed the effect of the AON on cell viability of AR-negative MIA $\mathrm{PaCa}-2$ cells. Treatment with three different concentrations of AON-ISE had no effect on MIA PaCa-2 cell viability (Fig. 4a). The reduction of cell viability was found to be a 

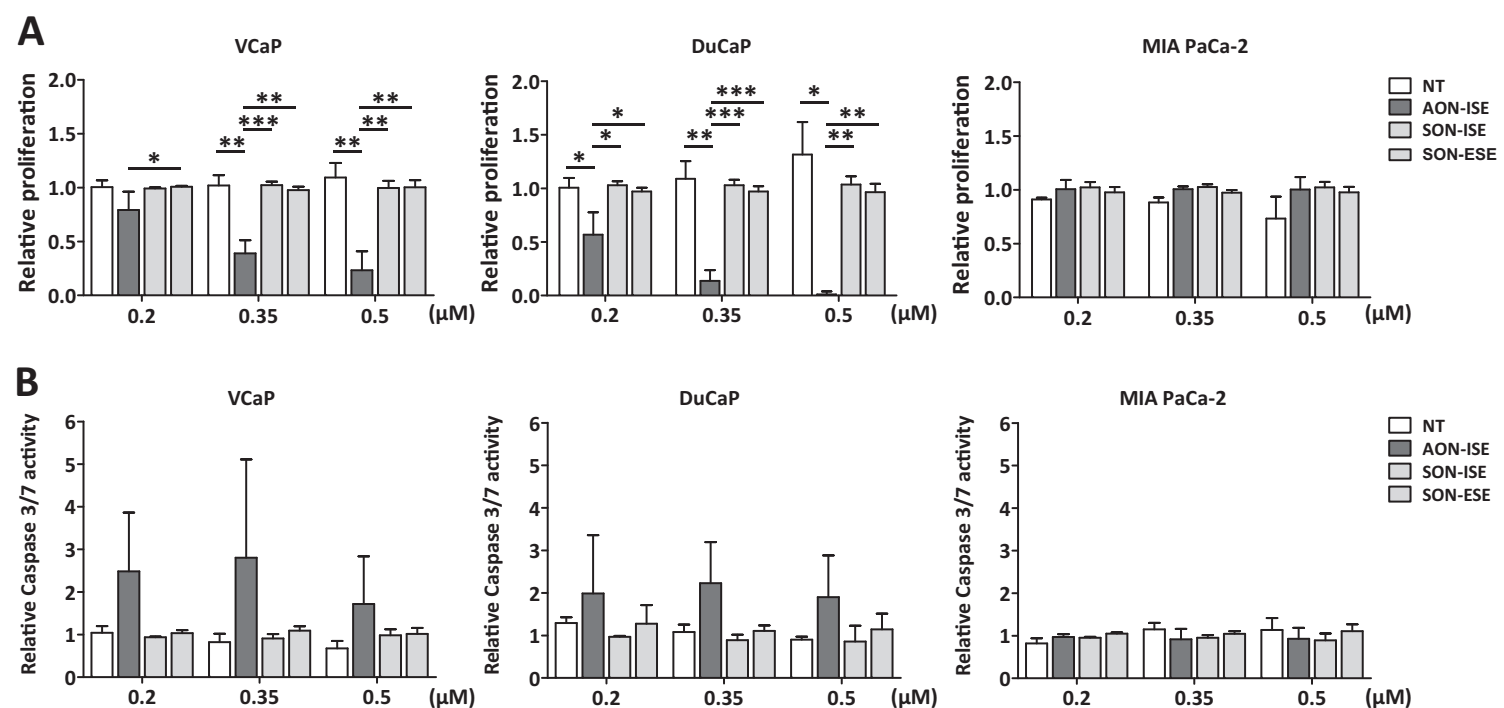

C
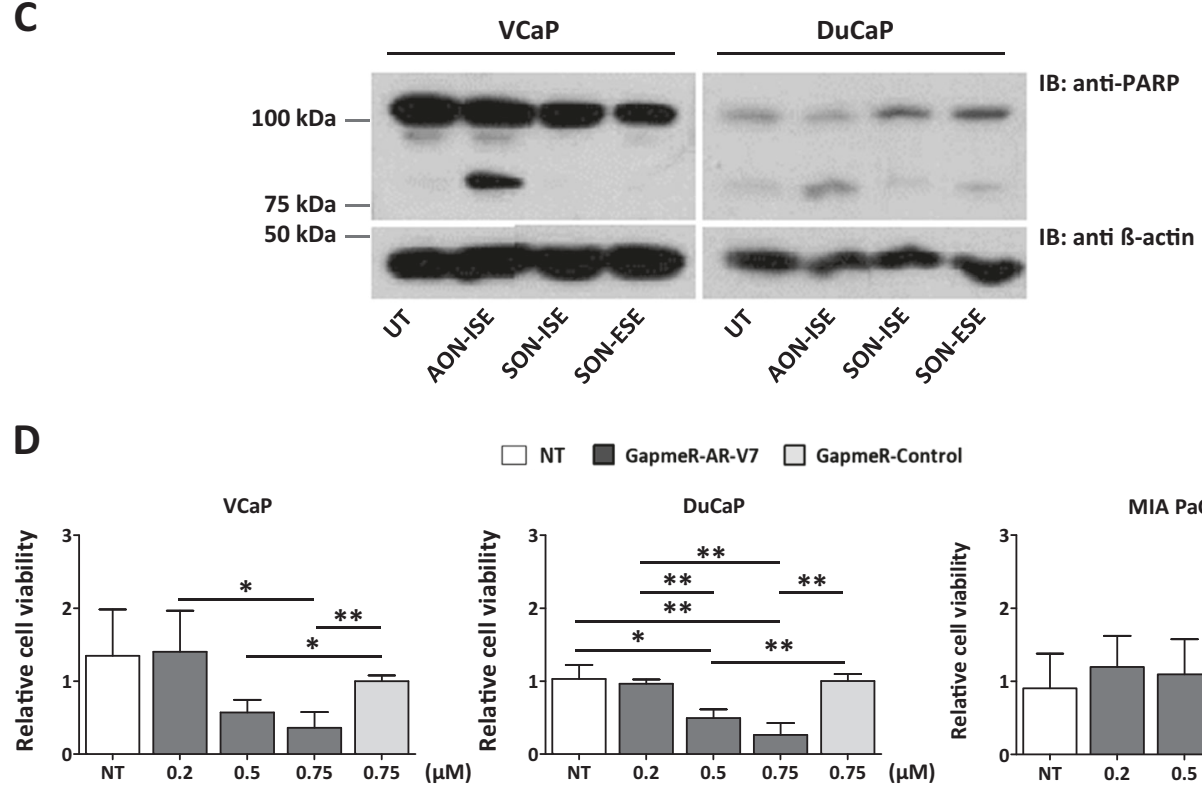

$\square$ NT $\square$ GapmeR-AR-V7 $\square$ GapmeR-Control
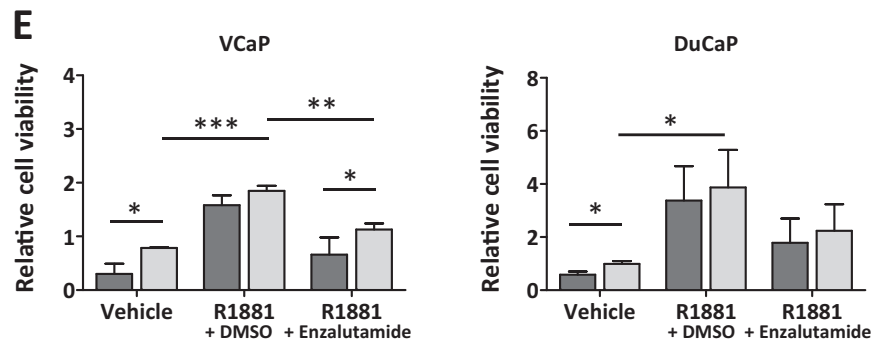

result of the induction of apoptosis, which was marked by an increase in Caspase-3/7 activity (Fig. 4b) and, consequently, a cleavage of the Poly (ADP-ribose) polymerase 1 (PARP-1) protein [25, 26] (Fig. 4c).

A GapmeR AON was designed to bind complementary to $A R-V 7$ mRNA, inducing its degradation by RNAse $\mathrm{H}$
(Supplementary Fig. S3 and Methods). GapmeR treatment caused a reduction in cell viability of both $\mathrm{DuCaP}$ and $\mathrm{VCaP}$ cells similarly to the AON-ISE treatment, without affecting MIA PaCa- 2 cell viability (Fig. $4 d$ ). This validated the association of $A R-V 7$ knockdown with the decrease in cell viability. 
Fig. 4 Effect of antisense oligonucleotide (AON)-intronic splicing enhancer (ISE) in cell viability and apoptosis. a Dose-dependent effect of AON-ISE-mediated androgen receptor (AR)-V7 knockdown on cell viability of DuCaP and VCaP cells compared with SON-treated cells. AR-negative MIA PaCa-2 cells were used as a negative control. Unpaired $t$-test; $* p<0.05 ; * * p<0.01 ; * * * p<0.001$. Bars represent the mean \pm SD of three independent experiments. b Induction of apoptosis, as determined by Caspase-3/7 induction, in DuCaP and VCaP cells after treatment with different doses of AON-ISE. AR-negative MIA $\mathrm{PaCa}-2$ cells were used as a negative control. Bars represent the mean \pm SD of three independent experiments. $\mathbf{c}$ Western blot analysis of fulllength and cleaved PARP-1 protein (anti-PARP) in DuCaP and $\mathrm{VCaP}$ cells, $96 \mathrm{~h}$ after transfection with $0.2 \mu \mathrm{M}$ AON-ISE or sense oligonucleotides. Protein levels of $\beta$-actin (anti- $\beta$-actin) was used as loading control. d Relative cell viability of DuCaP, VCaP, and MIA PaCa-2 cells after treatment with increasing doses of GapmeR-AR-V7, compared with GapmeR-Control-treated cells. Unpaired $t$-test; $* p<0.05$; $* * p<0.01$. Bars represent the mean $\pm \mathrm{SD}$ of three independent experiments. e Relative cell viability of AON-ISE or SON-ISEtransfected $(0.2 \mu \mathrm{M}) \mathrm{DuCaP}$ and $\mathrm{VCaP}$ cells grown in medium containing $0.1 \mathrm{nM} \mathrm{R} 1881$, or R1881 in combination with $2 \mu \mathrm{M}$ enzalutamide. Unpaired $t$-test; $* p<0.05 ; * * p<0.01 ; * * * p<0.001$. Bars represent the mean $\pm \mathrm{SD}$ of three independent experiments

Reactivation of full-length AR signaling was expected to revert the cell survival inhibitory effect of the AR-V7targeting AONs. Upon stimulation of DuCaP or $\mathrm{VCaP}$ cells with the synthetic androgen R1881, AR-FL activity became re-activated (Supplementary Fig. S2A) and cell viability was not significantly affected by AON-ISE compared with control SON-ISE-treated cells. Addition of enzalutamide to the medium re-sensitized cells to AON-ISE treatment (Fig. 4e), demonstrating that AON-ISE is able to inhibit AR-V7mediated and androgen-independent induction of cell proliferation.

Finally, to validate the effects of AON-ISE in a cell line with a different genetic background, the CRPC-derived 22Rv1 cell line was used. 22Rv1 cells express AR-V7 at a similar level than DuCaP and $\mathrm{VCaP}$ cells, and the ratio of $A R-V 7$-to- $A R-F L$ mRNA levels in $22 \mathrm{Rv} 1$ cells was higher than in these two cell lines, making it an ideal model to study AR-V7 activity (Supplementary Fig. S1A,B). AONISE treatment reduced cell viability of $22 \mathrm{Rv} 1$ cells by induction of apoptosis at all doses tested (Supplementary Fig. S4A,B). In addition, $A R-V 7$ and $U B E 2 C$ but not $A R-F L$ mRNA levels were significantly downregulated upon treatment with AON-ISE (Supplementary Fig. S4C).

\section{Effect of AON-ISE treatment over time}

To assess whether the effect on cell viability matches the downregulation of $U B E 2 C$, apoptosis and gene expression were assessed in time following AON-ISE treatment. A robust downregulation of $A R-V 7$ was observed in both $\mathrm{DuCaP}$ and VCaP cells at all time points up to 8 days after a single administration of the AON. The highest knockdown efficiency was observed between day 2 and day 4 hours after transfection with a slow decrease in knockdown thereafter. Consistently, expression levels of UBE2C followed a similar trend (Fig. 5a).

Caspase-3/7 induction was observed from day 2 onwards in both CRPC cell lines after treatment with AON-ISE (Fig. $5 b)$. Cell cycle profiling of these cells showed an increase in the sub-G1 cell population in AON-ISE-treated cells at day 3 after transfection (Fig. 5c). While the number of apoptotic cells in $\mathrm{VCaP}$ remained stable over time, an increase was noted in DuCaP cell cultures (Fig. 5c). Results in MIA $\mathrm{PaCa}-2$ cells showed no significant difference in the induction of caspase activity or the number of (sub-G1) apoptotic cells between AON and SON-treated cells (Supplementary Fig. S5).

\section{Discussion}

Therapeutic drugs for advanced PCa are designed to block androgen signaling, either by interfering with the androgen synthesis or by blocking AR androgen binding. Androgen deprivation therapy in patients with advanced or metastasized disease gives a clear survival benefit of about 18 months, but ultimately tumor cells become resistant leading to CRPC. While AR-targeting drugs efficiently target the full-length receptor, they have no effect on C-terminally truncated AR variants that increase upon CRPC development. Several AR variants, such as AR-V7, act as constitutively active transcription factors and promote androgenindependent cell proliferation. Here, we have described a proof of principle study where we employed AON technology to prevent splicing of CE3 of $A R-V 7$. These AONs reduced AR-V7 mRNA and protein levels, without affecting full-length AR mRNA and protein, and induced apoptosis of CRPC cells in a low androgen environment.

The publically available computer-based algorithms ACESCAN2 and ESEFinder were used to predict potential splicing enhancers within CE3 and its flanking regions. An ISE and an ESE site in and around CE3 of the AR premRNA have been reported. Mutations in these motifs impaired binding of splicing factors U2AF65 and ASF/SF2 and prevented the generation of an $A R-V 7$ transcript [12]. In our results, several ISE and ESE sites were predicted in and around CE3, and all (partially) overlapped with the ISE and ESE motifs described before [12]. This suggests that not a single ISE or ESE site may be pinpointed as most relevant for $A R-V 7$ mRNA splicing, and hence, AON-ISE and AONESE were designed to encompass all predicted ISE and ESE motifs, respectively. Comparing both AONs used in this study, AON-ESE affected the generation of $A R-V 7$ transcripts at a much lesser extent than AON-ISE. The AONISE sequence is directed not only against the predicted ISE motifs but also against the cryptic SA site. The fact that SA 
A

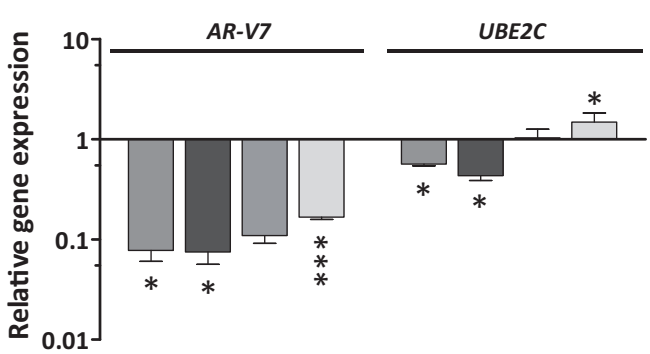

B

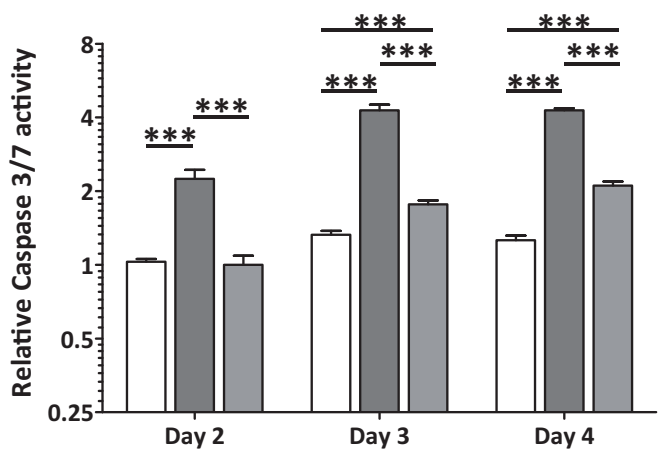

C
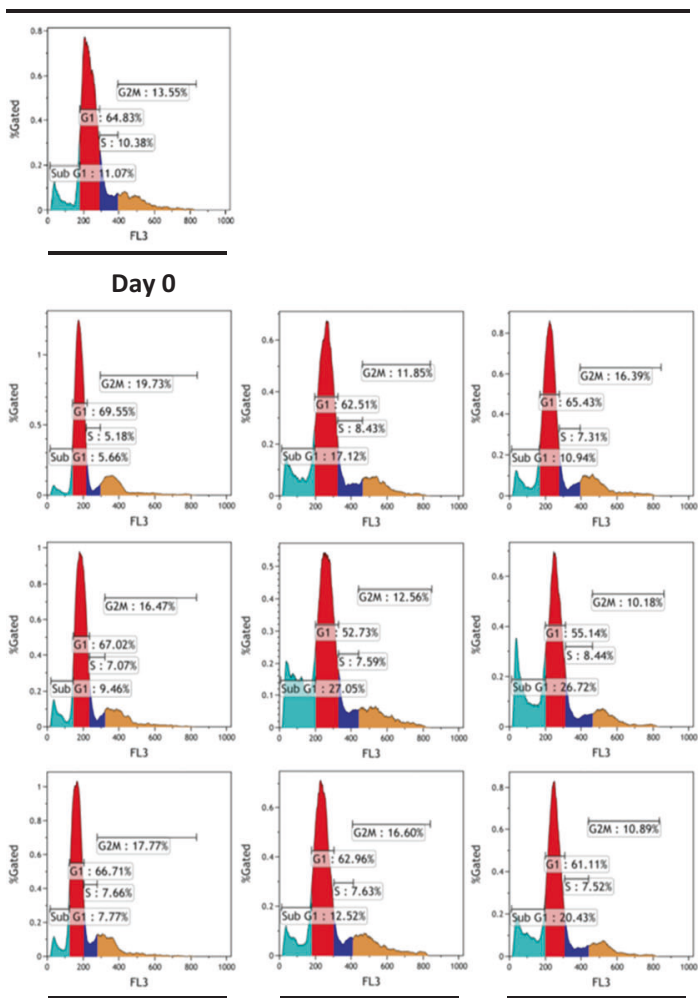

Day 2

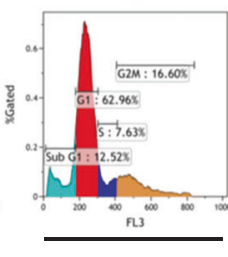

Day 3
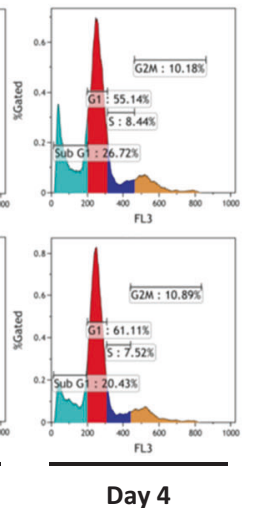

sites are essential for splicing, and enhancers only stimulate the splicing process, may explain why AON-ISE is more effective in blocking $A R-V 7$ splicing than AON-ESE.

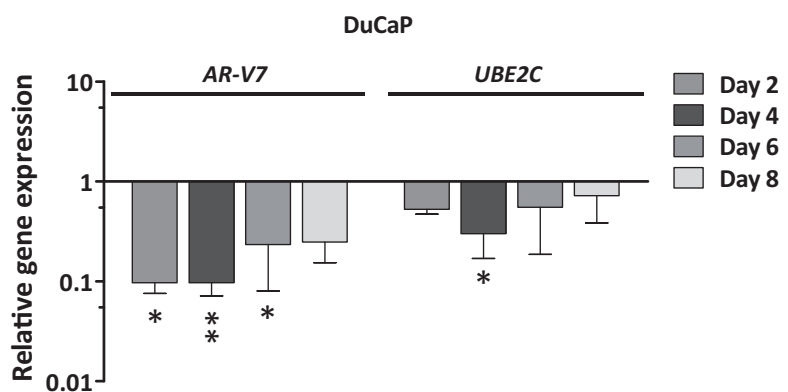

DuCaP

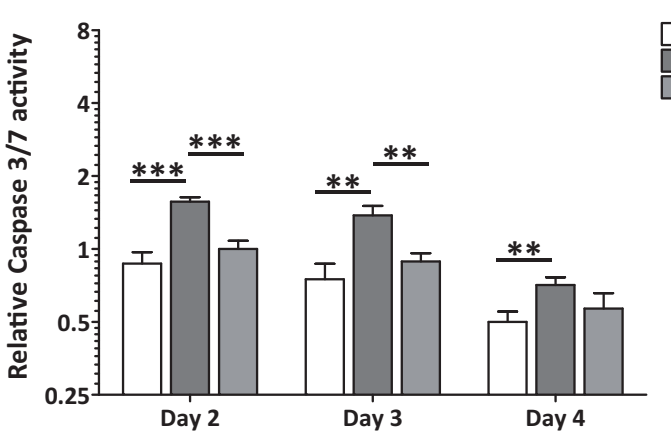

AON-ISE

SON-ISE
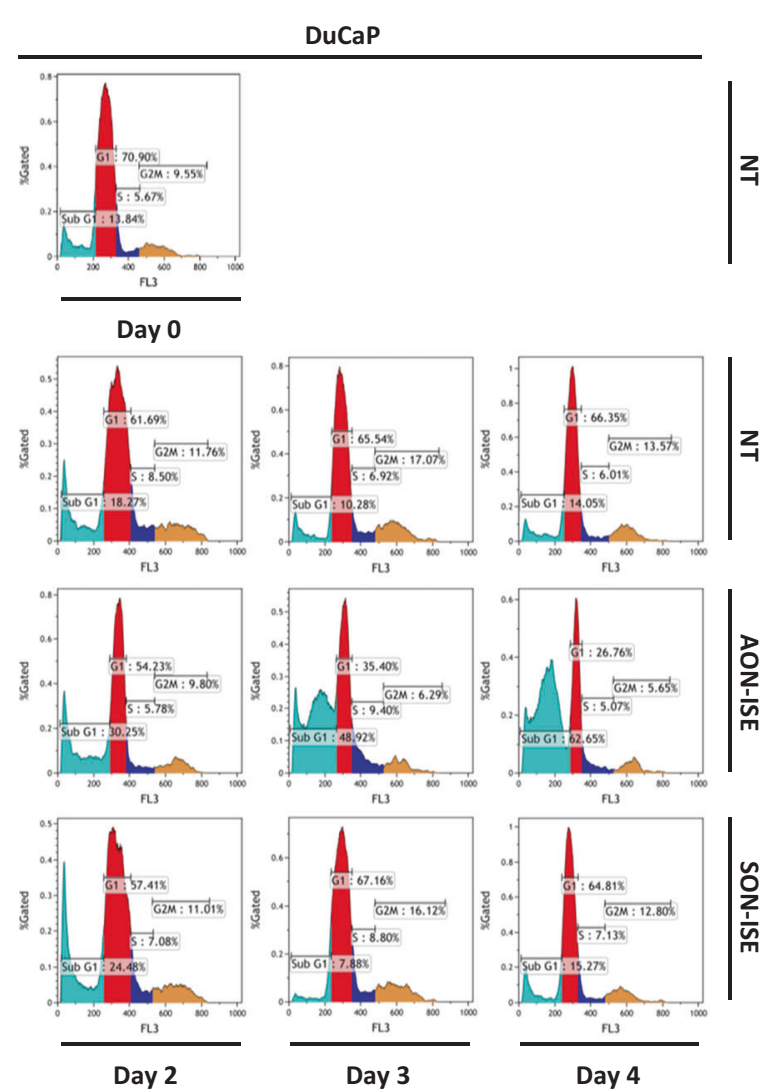

Furthermore, in the context of the AR transcript, the ISE enhancer may have superior activity over the ESE enhancer, as has been suggested by Liu et al. [12]. 
Fig. 5 Time follow-up of antisense oligonucleotide (AON)-intronic splicing enhancer's (ISE's) effect. a Expression levels of $A R-V 7$ and $U B E 2 C$ in $\mathrm{DuCaP}$ and $\mathrm{VCaP}$ cells, determined at different time points after treatment with $0.2 \mu \mathrm{M}$ of AON-ISE, normalized to values from un-transfected cells. Unpaired $t$-test; $* p<0.05$; ** $p<0.01$; *** $p<$ 0.001 . Bars represent the mean $\pm \mathrm{SD}$ of three independent experiments. b Relative Caspase-3/7 activity measured at different time points in DuCaP and VCaP cells treated with $0.2 \mu \mathrm{M}$ of AON-ISE or SON-ISE. Unpaired $t$-test; $* * p<0.01 ; * * * p<0.001$. Bars represent the mean \pm $\mathrm{SD}$ of three independent experiments. $\mathbf{c}$ Increase in $\mathrm{DuCaP}$ and $\mathrm{VCaP}$ sub-G1 cell population at day 3 and day 4, following knockdown of $A R-V 7$ by AON-ISE, as analyzed by propidium iodide staining and flow cytometry. Graphs show gated percentages of cells corresponding to sub-G1 (sky blue), G1 (red), S (blue), and G2/M (yellow) cell cycle phases

The use of a minigene was key to confirm the disturbance in splicing and to validate the importance of the predicted ISE and ESE sites. Upon transfection, both $A R-F L$ and $A R-V 7$ transcripts were expressed from the minigene construct. Interestingly, relative expression of the $A R-V 7$ transcript from the minigene was lower than that of $A R-F L$. Although this might suggest an intrinsic preference of splicing factors for binding to canonical splicing signals, this effect could as well be linked to the particular pool of splicing factors present in the AR-negative MIA PaCa- 2 cell line and therefore expression levels of the two mini transcripts could differ among cell line models.

Both of our AONs were generated with a phosphorothioate backbone and a 2 '-O-methyl group modification at the sugar chain, chemical modifications that make them resistant to RNAse activity. This could allow our AONs to remain stable throughout turnover of pre-existing AR-V7 proteins achieving a maximum effect. The physiological effect of AON-ISE occurred between day 3 and day 4, likely the time required for degradation of AR-V7 protein to a threshold that rendered cells sensitive to the oligo treatment.

Curiously, AON-ISE treatment in VCaP cells resulted in the downregulation of another AR mRNA variant, $A R-V 3$. The intronic region where CE3 and the predicted ISE sites lie, also harbors the cryptic exon that is present in the $A R-V 3$ splice variant [4, 27]. AON-ISE binding to its target sequence could disturb recruitment of splicing factors to one or more unknown splicing signals critical for the synthesis of $A R-V 3$ mRNA. Although AR-V3 is one of the most abundant variants, AR-V3 is considered inactive due to its permanent cytoplasmic localization, and therefore functional consequences of $A R-V 3$ knockdown are unlikely.

AON treatment demonstrated efficacy in three CRPC cell line models, but the response of each cell line to the treatment was not identical. At the mRNA and protein level, the effect of AON treatment seemed to be less pronounced in DuCaP than in VCaP cells. This probably reflects the difference in $A R$ transcript levels between these two cell lines.
$A R-F L$, as well as $A R-V 7$ mRNA expression, is markedly higher in $\mathrm{DuCaP}$ than in $\mathrm{VCaP}$, resulting from a higher $A R$ copy number (Supplementary Fig. S1C). This also could explain why the effect of AON-ISE on $A R-V 3$ mRNA levels was only visible in $\mathrm{VCaP}$ cells, but not in DuCaP. Contradictory to the knockdown efficiency, the effect of AONISE in cell viability of DuCaP was a lot more striking than in $\mathrm{VCaP}$ cells. DuCaP cells showed a stronger dosedependent sensitivity to AON-ISE treatment with a higher cleaved-to-full-length PARP-1 ratio and a consistent higher amount of apoptotic cells than the counterpart cell line. These observations indicated that the physiological dependency on AR-V7 for cell survival or proliferation, but not the knockdown efficiency per se dictates the sensitivity to AON-ISE treatment.

It has been shown recently that degradation products of AONs can affect cell proliferation and differentiation [28]. Sense oligonucleotides (SONs) having identical backbone modifications as the AONs were used in our experiments as negative controls. None of the SONs affected cell viability of the transfected cells, even at the highest dose tested $(0.5 \mu \mathrm{M})$, highlighting the specificity of our system. Furthermore, treatment with AON-ISE in the AR-negative MIA PaCa-2 showed no signs of AON-mediated toxicity at all concentrations tested.

Androgen stimulation has been reported to reduce $A R$ mRNA levels by repressing $A R$ transcription, a process that can be reverted upon treatment with AR inhibitors or following androgen withdrawal [29, 30]. In VCaP cells, this negative feedback was evident by a reduction in the expression levels of $A R-F L$ and $A R-V 7$ mRNA upon treatment with R1881. Transcripts levels were restored after addition of enzalutamide to the culturing medium. Here, androgen stimulation, as well as overexpression of $A R-V 7$, resulted in a significant induction of $U B E 2 C$ whereas enzalutamide treatment or AON-ISE-mediated knockdown of $A R-V 7$ promoted its downregulation, validating it as both an $A R-F L$ - and an $A R$ - $V 7$-target gene.

Another gene reported to be regulated by both AR-FL and AR-V7 is TMPRSS2 [4, 12, 24]. Fusion of the TMPRSS2 and ERG genes is the most prevalent gene fusion in prostate cancer, occurring in about $50 \%$ the cases [23]. Knockdown of TMPRSS2-ERG has been reported to inhibit cell proliferation in vitro [31], and knockdown of $E R G$ reduced tumor progression in vivo in an orthotopic mouse model [32]. AON-ISE-mediated $A R-V 7$ knockdown resulted in downregulation of TMPRSS2-ERG mRNA levels in $\mathrm{VCaP}$ cells, arguing for a role of AR-V7 in the maintenance of cell viability via TMPRSS2-ERG activation. The effect of AON-ISE in cell viability, however, was also observed in 22Rv1 cells (TMPRSS2-ERG fusion gene negative). Thus, AR-V7-mediated cell viability cannot be solely attributed to the regulation of TMPRSS2-ERG. 
Previous studies have shown that $U B E 2 C$ knockdown downregulates cell proliferation and activates the cellular apoptosis pathway [33]. AR-V7 has been reported to mediate $U B E 2 C$ transcriptional activation by direct occupancy of its promoter [24]. Interestingly, AON-ISE-mediated knockdown of $A R-V 7$ and the subsequent downregulation of $U B E 2 C$ were accompanied by an increase in Caspase-3/7 activity and an inhibition of androgen-independent cell proliferation. This suggests a role for $U B E 2 C$ as a key regulator of AR-V7-promoted cell viability.

Sustained cell proliferation in CRPC cells under castrate levels of androgens clearly demands for the development of new AR-targeted therapies. AONs have been shown to mediate significant biological effects in vitro and in vivo, reverting diverse disease phenotypes [34-37]. AON technology is nearing clinical relevance as it offers novel therapeutic opportunities for severe, untreatable or chronic diseases, including cancer [38-43]. Here, we present the first report on the use of a splice-switching AON technology in CRPC. Our results showed an AON-mediated specific and efficient knockdown of $A R-V 7$, which induces cell death in three CRPC-derived cell line models. These results certainly are promising and warrant further in vivo investigation.

Targeting of internal organs like the prostate or disseminated prostate cancer cells, typical for CRPC, would require systemic administration of AONs. Systemic administration of splice-switching AONs has demonstrated significant clinical benefits before. AON treatment corrected the open reading frame of the dystrophin DMD mRNA and ameliorated symptoms in Duchenne muscular dystrophy patients [44, 45]. Pharmacokinetic and pharmacodynamic profiling of our AONs is pivotal for further optimization of our AON as a drug system [46, 47]. The AON chemistry design and the choice of delivery method will ultimately determine its targeting efficacy.

\section{Materials and methods}

\section{Splicing signals prediction}

A 4-kb sequence containing an $A R$ intronic region known as CE3 and its flanking sequences (516-bp upstream and 2418bp downstream of CE3) was screened for the presence of intronic and exonic splice enhancer motifs. The publically available computer-based algorithms ACESCAN2 (http:// genes.mit.edu/ acescan2/index.html) and ESEFinder (http:// rulai.cshl.edu/cgi-bin/tools/ESE3/esefinder.cgi) were used to predict potential ISEs and ESEs, respectively. The cryptic splicing acceptor site was detected by screening the same sequence with the NetGene2 server (http://www.cbs.dtu.dk/ services/NetGene2/).

\section{Design of AONs}

Two RNA AONs, a 22 nucleotides long AON-ISE and a 19 nucleotides long AON-ESE, together with two control sense RNA oligonucleotides SON-ISE and SON-ESE were synthesized and modified with a phosphorothioate backbone and 2'-O-methyl groups at the sugar chain (Eurogentec, The Netherlands). Oligos were dissolved in nuclease-free water. A 20 nucleotides long GapmeR AONs, GapmeR-AR-V7, was designed using SFold software [48] (http://sfold.wadsworth.org/cgi-bin/index. pl). The chimeric GapmeR (RNA5-DNA10-RNA5) was chemically modified and synthesized as described above for the RNA AONs. The GapmeR sequence described by Wheeler et al. [49] was used as a control. Analytical ion exchange high-pressure liquid chromatography (HPLC) and matrix-assisted laser desorption/ionization time-offlight mass spectrometer (MALDI-TOF MS) were chosen to assess the purity of all oligonucleotides, and a purity of $>90 \%$ was considered as pure. AON sequences are listed in Supplementary Table S1.

\section{Cell culture}

The CRPC-derived 22Rv1 (ATCC\# CRL-2505), DuCaP, and VCaP (kindly provided by dr. Kenneth J. Pienta, Johns Hopkins, Baltimore, USA), the prostate cancer-derived LNCaP (ATCC\# CRL-1740), PC-3 (ATCC\# CRL-1435), and the bladder carcinoma-derived 5637 (ATCC\# HTB-9) cell lines were maintained as monolayer cultures in Roswell Park Memorial Institute (RPMI)-1640 medium (Invitrogen), supplemented with $2 \mathrm{mM}$ L-glutamine and $10 \%$ fetal calf serum (FCS; Sigma). Pancreatic carcinoma MIA-PaCa-2 cells (ATCC\# CRL-1420) were grown in Dulbecco's modified Eagle's medium (DMEM) (Invitrogen) with $4.5 \mathrm{~g} / \mathrm{ml}$ glucose and $1 \mathrm{mM}$ pyruvate, supplemented with 2 $\mathrm{mM}$ L-glutamine and $10 \% \mathrm{FCS}$ and $2.5 \%$ of horse serum (Invitrogen). For hormone stimulation experiments, $0.1 \mathrm{nM}$ of synthetic androgen R1881 (PerkinElmer) was added to the medium in combination with $2 \mu \mathrm{M}$ enzalutamide (Selleck Chemicals) or $0.2 \%$ dimethyl sulfoxide (as a vehicle control). Results were reproduced in at least three independent experiments. All cultures were maintained in a humidified atmosphere at $37{ }^{\circ} \mathrm{C}$ and $5 \% \mathrm{CO}_{2}$. Cell lines were authenticated in 2016 using the PowerPlex 21 system (Promega) by Eurofins Genomics (Germany). Cells were frequently tested for Mycoplasma infection, using a Mycoplasma-specific PCR, and propagated for no $>6$ months or 
30 passages after resuscitation from the authenticated stocks.

\section{Construction of minigene and AR-V7 expression vector}

The AR minigene was built according to sequence coordinates described by Liu et al. [12]. Briefly, three PCR amplicons were generated using Phusion High-Fidelity DNA Polymerase (New England Biolabs) and joined together by SOEing PCR. Genomic DNA from the (normal) human genomic DNA was used as the template to amplify AR exon 3, CE3, exon 4, and their flanking regions. Exon 4 was amplified including a downstream 447-base-pair flanking region. CE3 was amplified including 364-bp upstream and 1067-bp downstream flanking regions and $A R$ exon 4 amplicon included $469 \mathrm{bp}$ from the upstream flanking region. For SOEing PCR, all three fragments contain 20-bp overlapping sequences incorporated as overhangs in the forward and reverse primers. The assembled minigene was directionally cloned into the pEGFP-N3 vector (Clontech) between the BglII and NotI sites (thereby removing the eGFP region). For cloning of the eukaryotic expression vector pCMV-AR-V7, CE3 was amplified from human genomic DNA. The fusion between an exon 3 and CE3 was achieved by SOEing PCR using Phusion HighFidelity DNA Polymerase (New England Biolabs). The forward primers for the sewed amplicons were complemented with a $5^{\prime}$-GAGATG-3' overhang and a HindIII site, and the reverse primers with a $5^{\prime}$-GTTGTT- $3^{\prime}$ following an $\mathrm{MfeI}$ restriction site. The insert was directionally cloned into the pEGFP-N3-derived CMV-driven expression vector backbone vector. Correct cloning was verified by Sanger DNA sequence analysis of PCR products, purified using Wizard PCR preps DNA purification system (Promega). Primer sequences for cloning and sequencing analysis are listed in Supplementary Table S2.

\section{Transfection with AONs}

One day before transfection, 140,000 cells (DuCaP/VCaP) or 70,000 cells (22Rv1/MIA-PaCa-2) were seeded per well of a 24-well plate, in a total volume of $500 \mu \mathrm{l}$ medium. After trypsinization, cells were collected and seeded in charcoalstripped serum-containing medium to wash away traces of androgens previously reported to be present in FCS [50]. Transfection mixtures were prepared by combining oligonucleotides (AON/SON or GapmeRs) in a desired concentration with $\mathrm{X}$-tremeGENETM 9 transfection reagent (Roche), both dissolved in Opti-MEM I Reduced serumfree medium (Invitrogen). A mix of transfection reagent alone, i.e., without oligonucleotide, was used as nontransfected control. Mixes were incubated at room temperature for $15 \mathrm{~min}$ before addition to the cells in a dropwise manner. For overexpression studies, 140,000 $\mathrm{VCaP}$ cells were seeded per well in 24 -well plates. Twentyfour hours later, cells were transfected with $250 \mathrm{ng}$ of pCMV-AR-V7 expression vector or empty vector control. For minigene experiments, 70,000 MIA-PaCa- 2 cells were seeded per well in 24-well plates and after $24 \mathrm{~h}$, cells were co-transfected with $500 \mathrm{ng}$ of minigene or empty vector and $0.5 \mu \mathrm{M}$ of the desired oligonucleotide. All experiments were performed at least three times.

\section{RNA isolation and reverse transcription-PCR}

Total RNA was isolated using TRIzol reagent (Invitrogen) according to manufacturer's protocol. Concentration and purity of the RNA was determined on a Nanodrop-1000 spectrophotometer (Thermo Scientific). Subsequently, $2 \mu \mathrm{g}$ of total RNA was treated with DNaseI and used to synthesize complementary DNA using random hexamer primers and SuperScript II Reverse Transcriptase (Invitrogen). Real-time PCR (qPCR) analysis was performed using LightCycler 480 SYBR Green I Master Mix (Roche) and gene-specific primers (Supplementary Table S3). Crossingpoint $(\mathrm{Cp})$ values were determined using the LightCycler 480 SW 1.5 software (Roche). RNA not subjected to reverse transcriptase was used as a control for non-specific PCR amplification. Expression levels of the human heterochromatin protein 1 binding protein 3 (HP1BP3), the hypoxanthine phosphoribosyltransferase $1(H P R T 1)$ and the glyceraldehyde-3-phosphate dehydrogenase (GAPDH) genes were used for normalization and relative gene expression levels were calculated according to the mathematical model for relative quantification in real-time PCR [51]. To determine TMPRSS2-ERG fusion transcript levels, a forward primer directed to exon 1 of the TMPRSS2 transcript together with a reverse primer directed to exon 4 of the $E R G$ transcript were used [52].

\section{Western blot analysis}

One day before transfection, 1,200,000 (DuCaP/VCaP) cells were seeded in 10-cm dishes. When cells reached $70 \%$ confluency, oligonucleotide transfection was performed. Four days after transfection, cells were harvested and washed. Cell pellets were lysed using Laemmli lysis buffer ( $1 \mathrm{mM} \mathrm{CaCl}_{2}, 2 \%$ sodium dodecyl sulfate (SDS), $60 \mathrm{mM}$ Tris-Glycine $\mathrm{pH}$ 6.8) supplemented with 1:50 $\beta$-mercaptoethanol (Merck). Lysates were homogenized by sheering them through a $0.5 \times 25 \mathrm{~mm}$ syringe needle. Protein concentration was measured using the Odyssey CLx Imaging System (LI-COR) and Image Studio software (LI-COR), after staining with Coomassie brilliant blue (Merck) with serial dilutions of bovine serum albumin as a standard. A 
total of $100 \mu \mathrm{g}$ of protein was subjected to SDSpolyacrylamide gel electrophoresis using $7.5 \%$ polyacrylamide gels. Proteins were electrotransferred onto polyvinylidene fluoride membranes (Hybond $0.45 \mu \mathrm{m}$, Amersham Biosciences). Membranes were blocked for $1 \mathrm{~h}$ in phosphate-buffered saline with Tween-20 (PBS-T)/5\% non-fat dry milk and incubated overnight with the primary antibody. The mouse monoclonal-antibody anti-AR-V7 (Precision Antibody, \#AG10008), the rabbit polyclonal AR antibody N20 (Santa Cruz, SC-816), the rabbit monoclonal-antibody anti-PARP (Cell Signaling, \#46D11), and the mouse monoclonal-antibody anti- $\beta$-actin (SigmaAldrich, clone AC-15) were used, diluted 1:500, 1:50,000, 1:1000, and 1:5000 in PBS-T/5\% non-fat dry milk, respectively. The Horseradish peroxidase-conjugated donkey-anti-rabbit antibody (Amersham Biosciences, N4934) or sheep-anti-mouse antibody (Amersham Biosciences, NXA931) diluted 1:50,000 in PBS-T were used as secondary antibodies. Protein bands were detected using ECL and Hyperfilm (Amersham Biosciences). Results were reproduced in two independent experiments.

\section{Tissue collection and processing}

CRPC tissue $(n=20)$ was obtained by transurethral resection of prostate tumor tissue (TURP). TURP specimens were snap frozen in liquid nitrogen. Regions of CRPC tumors $(n=20)$ with high percentage of epithelial tumor cells $(>50 \%)$ were selected for cryo-sectioning. The use of patient materials was approved by the local ethics committee of the Radboud university medical center (CMO Arnhem-Nijmegen).

\section{Microarray analysis}

Microarray gene expression analysis on normal prostate, prostate cancer, and CRPC tissue samples were performed and described previously by Leyten et al. [53].

\section{Cell viability assay}

To assess cell viability, 10,000 (22Rv1), 20,000 cells (DuCaP/VCaP), or 500 cells (MIA-PaCa-2) were cultured in 96-well culture plates. Transfection with oligonucleotides was done $24 \mathrm{~h}$ after seeding. Four days after transfection, cell viability was measured using 3-(4,5-dimethylthiazol-2yl)-2,5-dephenyltetrazolium bromide (MTT, $1 \mathrm{mg} / \mathrm{ml}$ ) assays. Alternatively, cell viability was measured using CellTiter-Glo luminescence assays (Promega), following the manufacturer's instructions. Absorbance (at $490 \mathrm{~nm}$ ) and luminescence were measured using a Victor3 multilabel reader (PerkinElmer). Medium only was used as background control. To calculate the relative cell viability, cell viability values for each condition were normalized to the average of the cell viability values for control oligotransfected cells. Each experiment was performed in triplicate and repeated at least three times.

\section{Apoptosis assay}

In parallel to the cell viability assays, cells were seeded into 96-well plates for assessment of Caspase-3/7 activity using the Apo-ONE Homogenous Caspase-3/7 Assay (Promega), following manufacturer's instructions. After $4 \mathrm{~h}$ of incubation, luminescence was measured on a Victor3 multilabel reader (PerkinElmer). The luminescence signal from medium alone was used as background. Caspase-3/7 activity was normalized to values in control oligo-transfected cells. Each experiment was performed in triplicate and repeated at least three times.

\section{Cell cycle analysis}

One day before transfection, 280,000 cells ( $\mathrm{DuCaP} / \mathrm{VCaP})$ were seeded per well of a 12-well plate. The next day, cells were transfected with oligonucleotides as described above. Samples were harvested at different time points after transfection. Briefly, cells were harvested and washed with $0.9 \% \mathrm{NaCl}$. Cell pellets were resuspended in Hank's balanced salt solution (Invitrogen) and cells were fixed with ice-cold ethanol (58\%). Fixated cells were centrifuged, resuspended in PBS, and treated with RNase A $(100 \mu \mathrm{g} / \mathrm{ml}$, Sigma) for $40 \mathrm{~min}$ at $37^{\circ} \mathrm{C}$. Subsequently, cells were stained with propidium iodide ( $40 \mu \mathrm{g} / \mathrm{ml}$, Sigma) for $15 \mathrm{~min}$ in the dark. The samples were analyzed on a FC500 Flow Cytometer (Beckman-Coulter) and histograms were created and analyzed using Kaluza ${ }^{\circledR}$ Flow Analysis software (Beckman-Coulter). Results were reproduced in two independent experiments.

\section{Statistical analysis}

The data are presented as means $\pm \mathrm{SD}$ from at least three independent experiments. Two-tailed paired and unpaired $t$ tests were performed using GraphPad Prism (GraphPad Software, Inc.). Pearson correlation coefficients were used to determine the relationships between relative gene expression profiles, considering a $95 \%$ confidence interval. A $p$-value of $<0.05$ was considered statistically significant and $p<0.05$ is represented by one star $(*), p<0.01$ is represented by two stars $(* *)$, and $p<0.001$ is represented by three stars $(* * *)$.

Acknowledgements The authors would like to thank Sophie Cools, Cornelius Jansen, and Mirjam de Weijert for their excellent technical assistance. We also would like to thank Dr. Kenneth J. Pienta M.D. from Johns Hopkins for kindly providing us with the DuCaP and 
$\mathrm{VCaP}$ cell lines. This work was sponsored by an NWO grant (Project number: 022.003.007).

\section{Compliance with ethical standards}

Conflict of interest The authors declare that they have no conflict of interest.

Publisher's note: Springer Nature remains neutral with regard to jurisdictional claims in published maps and institutional affiliations.

Open Access This article is licensed under a Creative Commons Attribution 4.0 International License, which permits use, sharing, adaptation, distribution and reproduction in any medium or format, as long as you give appropriate credit to the original author(s) and the source, provide a link to the Creative Commons license, and indicate if changes were made. The images or other third party material in this article are included in the article's Creative Commons license, unless indicated otherwise in a credit line to the material. If material is not included in the article's Creative Commons license and your intended use is not permitted by statutory regulation or exceeds the permitted use, you will need to obtain permission directly from the copyright holder. To view a copy of this license, visit http://creativecommons. org/licenses/by/4.0/.

\section{References}

1. Cornford P, Bellmunt J, Bolla M, Briers E, De Santis M, Gross T, et al. EAU-ESTRO-SIOG Guidelines on Prostate Cancer. Part II: treatment of relapsing, metastatic, and castration-resistant prostate cancer. Eur Urol. 2017;71:630-42.

2. Scher HI, Sawyers CL. Biology of progressive, castration-resistant prostate cancer: directed therapies targeting the androgen-receptor signaling axis. J Clin Oncol. 2005;23:8253-61.

3. Armstrong AJ, Garrett-Mayer E, De Wit R, Tannock I, Eisenberger M. Prediction of survival following first-line chemotherapy in men with castration-resistant metastatic prostate cancer. Clin Cancer Res. 2010;16:203-11.

4. Hu R, Dunn TA, Wei S, Isharwal S, Veltri RW, Humphreys E, et al. Ligand-independent androgen receptor variants derived from splicing of cryptic exons signify hormone-refractory prostate cancer. Cancer Res. 2009;69:16-22.

5. Guo Z, Yang X, Sun F, Jiang R, Linn DE, Chen H, et al. A novel androgen receptor splice variant is up-regulated during prostate cancer progression and promotes androgen depletion-resistant growth. Cancer Res. 2009;69:2305-13.

6. Hörnberg E, Ylitalo EB, Crnalic S, Antti H, Stattin P, Widmark A, et al. Expression of androgen receptor splice variants in prostate cancer bone metastases is associated with castration-resistance and short survival. PLoS ONE. 2011;6:e19059.

7. Antonarakis ES, Lu C, Wang H, Luber B, Nakazawa M, Roeser $\mathrm{JC}$, et al. AR-V7 and resistance to enzalutamide and abiraterone in prostate cancer. N Engl J Med. 2014;371:1028-38.

8. Li Y, Chan SC, Brand LJ, Hwang TH, Silverstein KA, Dehm SM. Androgen receptor splice variants mediate enzalutamide resistance in castration-resistant prostate cancer cell lines. Cancer Res. 2013:73:483-9.

9. Nadiminty N, Tummala R, Liu C, Yang J, Lou W, Evans CP, et al. NF-kappaB2/p52 induces resistance to enzalutamide in prostate cancer: role of androgen receptor and its variants. Mol Cancer Ther. 2013;12:1629-37.

10. Mostaghel EA, Marck BT, Plymate SR, Vessella RL, Balk S, Matsumoto AM, et al. Resistance to CYP17A1 inhibition with abiraterone in castration-resistant prostate cancer: induction of steroidogenesis and androgen receptor splice variants. Clin Cancer Res. 2011;17:5913-25.

11. Hu R, Lu C, Mostaghel Ea, Yegnasubramanian S, Gurel M, Tannahill C, et al. Distinct transcriptional programs mediated by the ligand-dependent full-length androgen receptor and its splice variants in castration-resistant prostate cancer. Cancer Res. 2012;72:3457-62.

12. Liu LL, Xie N, Sun S, Plymate S, Mostaghel E, Dong X. Mechanisms of the androgen receptor splicing in prostate cancer cells. Oncogene. 2014;33:3140-50.

13. Sazani P, Kole R. Therapeutic potential of antisense oligonucleotides as modulators of alternative splicing. J Clin Invest. 2003;112:481-6.

14. Havens MA, Hastings ML. Splice-switching antisense oligonucleotides as therapeutic drugs. Nucleic Acids Res. 2016;44:654963.

15. Yeo GW, Van Nostrand E, Holste D, Poggio T, Burge CB. Identification and analysis of alternative splicing events conserved in human and mouse. Proc Natl Acad Sci USA. 2005;102:2850-5.

16. Cartegni L, Wang J, Zhu Z, Zhang MQ, Krainer AR. ESEfinder: a web resource to identify exonic splicing enhancers. Nucleic Acids Res. 2003;31:3568-71.

17. Smith PJ, Zhang C, Wang J, Chew SL, Zhang MQ, Krainer AR. An increased specificity score matrix for the prediction of SF2/ ASF-specific exonic splicing enhancers. Hum Mol Genet. 2006;15:2490-508.

18. Hebsgaard SM, Korning PG, Tolstrup N, Engelbrecht J, Rouze P, Brunak S. Splice site prediction in Arabidopsis thaliana premRNA by combining local and global sequence information. Nucleic Acids Res. 1996;24:3439-52.

19. De Clercq E, Eckstein F, Sternbach H, Merigan TC. Interferon induction by and ribonuclease sensitivity of thiophosphatesubstituted polyribonucleotides. Antimicrob Agents Chemother. 1969;9:187-91.

20. Sproat BS, Lamond AI, Beijer B, Neuner P, Ryder U. Highly efficient chemical synthesis of 2'-O-methyloligoribonucleotides and tetrabiotinylated derivatives; novel probes that are resistant to degradation by RNA or DNA specific nucleases. Nucleic Acids Res. 1989;17:3373-86.

21. Manoharan M. 2'-Carbohydrate modifications in antisense oligonucleotide therapy: importance of conformation, configuration and conjugation. Biochim Biophys Acta. 1999;1489:117-30.

22. Zhang X, Morrissey C, Sun S, Ketchandji M, Nelson PS, True LD et al. Androgen receptor variants occur frequently in castration resistant prostate cancer metastases. PLoS ONE 2011. https://doi. org/10.1371/journal.pone.0027970.

23. Tomlins SA, Rhodes DR, Perner S, Dhanasekaran SM, Mehra $\mathrm{R}$, Sun X-W, et al. Recurrent fusion of TMPRSS2 and ETS transcription factor genes in prostate cancer. Science. 2005;310:644-8.

24. Cao B, Qi Y, Zhang G, Xu D, Zhan Y, Alvarez X, et al. Androgen receptor splice variants activating the full-length receptor in mediating resistance to androgen-directed therapy. Oncotarget. 2014:5:1646-56.

25. Germain M, Affar EB, D'Amours D, Dixit VM, Salvesen GS, Poirier GG. Cleavage of automodified poly(ADP-ribose) polymerase during apoptosis. Evidence for involvement of caspase-7. J Biol Chem. 1999;274:28379-84.

26. D'Amours D, Germain M, Orth K, Dixit VM, Poirier GG. Proteolysis of poly(ADP-ribose) polymerase by caspase 3: kinetics of cleavage of mono(ADP-ribosyl)ated and DNA-bound substrates. Radiat Res. 1998;150:3-10.

27. Dehm SM, Schmidt LJ, Heemers HV, Vessella RL, Tindall DJ. Splicing of a novel androgen receptor exon generates a constitutively active androgen receptor that mediates prostate cancer therapy resistance. Cancer Res. 2008;68:5469-77. 
28. Wagner RW. Gene inhibition using antisense oligodeoxynucleotides. Nature. 1994;372:333-5.

29. Krongrad A, Wilson CM, Wilson JD, Allman DR, McPhaul MJ. Androgen increases androgen receptor protein while decreasing receptor mRNA in LNCaP cells. Mol Cell Endocrinol. 1991;76:79-88.

30. Cai C, He HH, Chen S, Coleman I, Wang H, Fang Z, et al. Androgen receptor gene expression in prostate cancer is directly suppressed by the androgen receptor through recruitment of lysine-specific demethylase 1. Cancer Cell. 2011;20:457-71.

31. Wang J, Cai Y, Yu W, Ren C, Spencer DM, Ittmann M. Pleiotropic biological activities of alternatively spliced TMPRSS2/ERG fusion gene transcripts. Cancer Res. 2008;68:8516-24.

32. Mounir Z, Lin F, Lin VG, Korn JM, Yu Y, Valdez R, et al. TMPRSS2:ERG blocks neuroendocrine and luminal cell differentiation to maintain prostate cancer proliferation. Oncogene. 2014;34:3815.

33. Chou CP, Huang NC, Jhuang SJ, Pan HBen, Peng NJ, Cheng JT, et al. Ubiquitin-conjugating enzyme UBE2C is highly expressed in breast microcalcification lesions. PLoS ONE. 2014;9:1-11.

34. Wraight CJ, White PJ, McKean SC, Fogarty RD, Venables DJ, Liepe IJ, et al. Reversal of epidermal hyperproliferation in psoriasis by insulin-like growth factor I receptor antisense oligonucleotides. Nat Biotechnol. 2000;18:521-6.

35. Scoles DR, Meera P, Schneider MD, Paul S, Dansithong W, Figueroa KP, et al. Antisense oligonucleotide therapy for spinocerebellar ataxia type 2. Nature. 2017;544:362-6.

36. Tasfaout H, Buono S, Guo S, Kretz C, Messaddeq N, Booten S, et al. Antisense oligonucleotide-mediated Dnm2 knockdown prevents and reverts myotubular myopathy in mice. Nat Commun. 2017;8:15661.

37. Yamamoto Y, Loriot Y, Beraldi E, Zhang F, Wyatt AW, Nakouzi $\mathrm{NAl}$, et al. Generation 2.5 antisense oligonucleotides targeting the androgen receptor and its splice variants suppress enzalutamideresistant prostate cancer cell growth. Clin Cancer Res. 2015;21:1675-87.

38. Moulder SL, Symmans WF, Booser DJ, Madden TL, Lipsanen C, Yuan L, et al. Phase I/II study of G3139 (Bcl-2 antisense oligonucleotide) in combination with doxorubicin and docetaxel in breast cancer. Clin Cancer Res. 2008;14:7909-16.

39. Beer TM, Hotte SJ, Saad F, Alekseev B, Matveev V, Flechon A, et al. Custirsen (OGX-011) combined with cabazitaxel and prednisone versus cabazitaxel and prednisone alone in patients with metastatic castration-resistant prostate cancer previously treated with docetaxel (AFFINITY): a randomised, open-label, international, ph. Lancet Oncol. 2017;18:1532-42.

40. Hache M, Swoboda KJ, Sethna N, Farrow-Gillespie A, Khandji $\mathrm{A}, \mathrm{Xia} \mathrm{S}$, et al. Intrathecal injections in children with spinal muscular atrophy: Nusinersen clinical trial experience. J Child Neurol. 2016;31:899-906.
41. Chiriboga CA, Swoboda KJ, Darras BT, Iannaccone ST, Montes J, De Vivo DC, et al. Results from a phase 1 study of nusinersen (ISIS-SMN(Rx)) in children with spinal muscular atrophy. Neurology. 2016;86:890-7.

42. Bianchini D, Omlin a, Pezaro C, Lorente D, Ferraldeschi R, Mukherji D, et al. First-in-human phase I study of EZN-4176, a locked nucleic acid antisense oligonucleotide to exon 4 of the androgen receptor mRNA in patients with castration-resistant prostate cancer. Br J Cancer. 2013;109:2579-86.

43. Saad F, Hotte SJ, North SA, Eigl BJ, Chi KN, Czaykowski P, et al. A phase II randomized study of custirsen (OGX-011) combination therapy in patients with poor-risk hormone refractory prostate cancer (HRPC) who relapsed on or within six months of 1st-line docetaxel therapy. J Clin Oncol. 2008;26:5002.

44. Mendell JR, Goemans N, Lowes LP, Alfano LN, Berry K, Shao J, et al. Longitudinal effect of eteplirsen versus historical control on ambulation in Duchenne muscular dystrophy. Ann Neurol. 2016;79:257-71.

45. Voit T, Topaloglu H, Straub V, Muntoni F, Deconinck N, Campion G, et al. Safety and efficacy of drisapersen for the treatment of Duchenne muscular dystrophy (DEMAND II): an exploratory, randomised, placebo-controlled phase 2 study. Lancet Neurol. 2014;13:987-96.

46. Geary RS, Norris D, Yu R, Bennett CF. Pharmacokinetics, biodistribution and cell uptake of antisense oligonucleotides. Adv Drug Deliv Rev. 2015;87:46-51.

47. Verhaart IEC, Tanganyika-de Winter CL, Karnaoukh TG, Kolfschoten IGM, de Kimpe SJ, van Deutekom JCT. et al. Dosedependent pharmacokinetic profiles of 2'-O-methyl phosphorothioate antisense oligonucleotidesin $\mathrm{mdx}$ mice. Nucleic Acid Ther. 2013;23:228-37.

48. Ding Y, Chan CY, Lawrence CE. Sfold web server for statistical folding and rational design of nucleic acids. Nucleic Acids Res. 2004;32:W135-41.

49. Wheeler TM, Leger AJ, Pandey SK, MacLeod AR, Nakamori M, Cheng SH, et al. Targeting nuclear RNA for in vivo correction of myotonic dystrophy. Nature. 2012;488:111-5.

50. Sedelaar JPM, Isaacs JT. Tissue culture media supplemented with $10 \%$ fetal calf serum contains a castrate level of testosterone. Prostate. 2009;69:1724-9.

51. Pfaffl MW. A new mathematical model for relative quantification in real-time RT-PCR. Nucleic Acids Res. 2001;29:e45.

52. Hessels D, Smit FP, Verhaegh GW, Witjes JA, Cornel EB, Schalken JA. Detection of TMPRSS2-ERG fusion transcripts and prostate cancer antigen 3 in urinary sediments may improve diagnosis of prostate cancer. Clin Cancer Res. 2007;13:5103-8.

53. Leyten GHJM, Hessels D, Smit FP, Jannink SA, de Jong H, Melchers WJG, et al. Identification of a candidate gene panel for the early diagnosis of prostate cancer. Clin Cancer Res. 2015;21:3061-70. 